\title{
BMJ Open Experience of miscarriage: an interpretative phenomenological analysis
}

\author{
S Meaney, ${ }^{1,2}$ P Corcoran, ${ }^{1}$ N Spillane,${ }^{2}$ K O’Donoghue ${ }^{2,3}$
}

To cite: Meaney S,

Corcoran P, Spillane N, et al. Experience of miscarriage: an interpretative phenomenological analysis. BMJ Open 2017;7:e011382. doi:10.1136/bmjopen-2016011382

- Prepublication history for this paper is available online. To view these files please visit the journal online (http://dx.doi.org/10.1136/ bmjopen-2016-011382).

Received 3 February 2016 Revised 16 June 2016 Accepted 20 July 2016

\section{CrossMark}

\footnotetext{
${ }^{1}$ National Perinatal Epidemiology Centre, University College Cork, Ireland

${ }^{2}$ Pregnancy Loss Research Group, Dept. of Obstetrics and Gynaecology, University College Cork, Ireland

${ }^{3}$ The Irish Centre for Fetal and Neonatal Translational Research (INFANT), University College Cork, Ireland
}

Correspondence to Dr S Meaney; s.meaney@ucc.ie

\section{ABSTRACT}

Objective: The objective of the study was to explore the experiences of those who have experienced miscarriage, focusing on men's and women's accounts of miscarriage.

Design: This was a qualitative study using a phenomenological framework. Following in-depth semistructured interviews, analysis was undertaken in order to identify superordinate themes relating to their experience of miscarriage.

Setting: A large tertiary-level maternity hospital in Ireland.

Participants: A purposive sample of 16 participants, comprising 10 women and 6 men, was recruited.

Results: 6 superordinate themes in relation to the participant's experience of miscarriage were identified:

(1) acknowledgement of miscarriage as a valid loss;

(2) misperceptions of miscarriage; (3) the hospital environment, management of miscarriage; (4) support and coping; (5) reproductive history; and (6) implications for future pregnancies.

Conclusions: One of the key findings illustrates a need for increased awareness in relation to miscarriage. The study also indicates that the experience of miscarriage has a considerable impact on men and women. This study highlights that a thorough investigation of the underlying causes of miscarriage and continuity of care in subsequent pregnancies are priorities for those who experience miscarriage.

Consideration should be given to the manner in which women who have not experienced recurrent miscarriage but have other potential risk factors for miscarriage could be followed up in clinical practice.

\section{INTRODUCTION}

Improvements in the quality of care provided during pregnancy have led to substantial reductions in perinatal and maternal mortality as well as a reduction in other adverse pregnancy outcomes. ${ }^{1} \quad$ However, these advances have had little effect on the high rate of miscarriage with between $20 \%$ and $30 \%$ of pregnancies ending in miscarriage. ${ }^{12}$ Until now, much of the research has aimed to identify potential risk factors as the underlying aetiology of miscarriage is not well understood. ${ }^{2}$

\section{Strengths and limitations of this study}

- This study uses interpretative phenomenological analysis in order to interpret the experience of miscarriage.

- Much of the research in relation to pregnancy loss is focused on women's experience. Purposive sampling was undertaken to ensure that both women's and men's experiences were included in this study.

- Participants from this study were drawn from a large tertiary maternity hospital with a dedicated pregnancy loss clinic and it may be possible that their experiences may differ from those who attend a hospital where such a clinic is not available to them.

- Miscarriage is the most common adverse outcome in pregnancy. This study highlights the need for the provision of appropriate clinical information as well as supportive information when counselling individuals who experienced miscarriage.

Studies indicate the need for familial and social support following miscarriage as it can be an extremely painful and upsetting experience, ${ }^{3} 4$ with some women experiencing medical complications. ${ }^{5}{ }^{6}$ Quantitative studies indicate that the experience of miscarriage can negatively impact on the men's and women's psychological well-being. ${ }^{4}$ 7-14 These studies also report that the high levels of stress and anxiety experienced ${ }^{7-9}$ can endure for 6-12 months following miscarriage. ${ }^{8}$

In contrast, an interventional study in the USA examined the changes of women's feeling over the course of year following miscarriage. Swanson et $a l^{15}$ found that women's responses recorded at 1 year were not significantly different from those recorded at 6 weeks. Considering the high incidence of miscarriage and the reported impact on the emotional well-being of people, there are comparatively few studies that have qualitatively examined the experience of miscarriage. Of these, most studies focused on the 
women's experience of miscarriage ${ }^{316-18}$ whereby the male experience has been reported based on the women's perspective. ${ }^{16}{ }^{19}$ Our study builds on these findings as it aimed to explore the experiences of people who have experienced miscarriage. The purpose of this study was to focus on men's and women's accounts of miscarriage. Through a qualitative analysis, the objective of the study was to gain detailed insight into their expectations of pregnancy as well as their experience of miscarriage diagnosis and management.

\section{METHODS}

An interpretative phenomenological analysis (IPA) was undertaken as this approach has its theoretical foundations in phenomenology. ${ }^{20-22}$ Phenomenology examines perceptions and engages with the way individuals reflect on the experiences they deem significant in their lives. ${ }^{21}$ Researchers who engage in IPA acknowledge how experience is subjective and is therefore only accessible through interpretation. ${ }^{20}$ IPA has an ideographic approach which allows the researcher to rigorously explore how these experiences may affect a person. ${ }^{20}$ IPA has increasingly been used in healthcare research as its ideographic approach facilitates researchers to rigorously explore how specific phenomena may affect a patient and consequently will impact on patient care. $^{20}$

The study took place in a large tertiary-level Irish maternity hospital. The sample was initially recruited from a list of women who had previously participated in a prospective cohort study regarding miscarriage ${ }^{23}$ and agreed to be contacted for future research. It is important to note that there are geographical variations for the definition of miscarriage. For the purposes of this study, miscarriage was defined as any pregnancy loss which occurred before 24 weeks gestation in a fetus weighing $<500 \mathrm{~g}$. Participants were eligible for the study if they were aged 18 years and older and had experienced one or more miscarriages. Letters were sent to invite women and their partners to participate in the present study by the primary author. If an opt-out form was not returned, the primary author made contact to provide more detailed information about the study. Over the course of the study, six opt-out forms were returned. Three participants were recruited using snowballing techniques, through contact with the Miscarriage Association of Ireland and/or through the bereavement and loss hospital team. Information on the study was forwarded to them and they made contact with the primary author to become involved in the study. None of the participants were known to the researcher.

The primary author recruited until data saturation was met. The final sample consisted of 16 participants (10 female and 6 male), 4 of whom were couples (table 1 ). All the participants signed an informed consent and were interviewed individually, by the primary author (an experienced female qualitative researcher), using a semistructured interview schedule (table 2). All the interviews were conducted in a room onsite in the maternity hospital or a location convenient to the participant, with the exception of one interview that was undertaken by telephone under participant request. Each interview was digitally recorded and contemporaneous notes were taken immediately after each interview. The average interview was $43 \mathrm{~min}$, ranging from 28 to $69 \mathrm{~min}$ in length.

The IPA involved: first listening and re-reading the interviews a number of times to ensure that a general sense of the participants' accounts were acquired. Second, emergent themes were initially identified which were then

\begin{tabular}{|c|c|c|c|c|c|c|c|c|}
\hline Participant & Parent & Couple & $\begin{array}{l}\text { Number of } \\
\text { miscarriage }\end{array}$ & $\begin{array}{l}\text { Time in months } \\
\text { since most } \\
\text { recent loss }\end{array}$ & $\begin{array}{l}\text { Gestation } \\
\text { of most } \\
\text { recent loss }\end{array}$ & $\begin{array}{l}\text { Living } \\
\text { children }\end{array}$ & Management & $\begin{array}{l}\text { Patient } \\
\text { status }\end{array}$ \\
\hline 1 & Female & 1 & 2 & 18 & 6 & 0 & Expectant & Public \\
\hline 2 & Male & 1 & 2 & 18 & 6 & 0 & Expectant & Public \\
\hline 3 & Female & NA & 4 & 13 & 10 & 1 & Medical & Public \\
\hline 4 & Female & NA & 3 & 7 & 9 & 1 & Medical & Public \\
\hline 5 & Female & NA & 4 & 18 & 5 & 1 & Medical & Private \\
\hline 6 & Female & 2 & 3 & 19 & 15 & 3 & Surgical & Private \\
\hline 7 & Female & NA & 2 & 14 & 11 & 2 & Medical & Private \\
\hline 8 & Female & 3 & 7 & 20 & 14 & 1 & Expectant & Public \\
\hline 9 & Male & 3 & 7 & 20 & 14 & 1 & Expectant & Public \\
\hline 10 & Female & NA & 2 & 18 & 12 & 3 & Surgical & Public \\
\hline 11 & Female & NA & 3 & 8 & 10 & 3 & Medical & Public \\
\hline 12 & Female & 4 & 2 & 16 & 9 & 3 & Expectant & Public \\
\hline 13 & Male & NA & 3 & 27 & 16 & 3 & Medical & Public \\
\hline 14 & Male & 4 & 2 & 16 & 9 & 3 & Expectant & Public \\
\hline 15 & Male & NA & 2 & 96 & 7 & 2 & Expectant & Public \\
\hline 16 & Male & 2 & 3 & 19 & 15 & 3 & Surgical & Private \\
\hline
\end{tabular}


Table 2 Overview of the semistructured interview schedule

\begin{tabular}{|c|c|}
\hline Area of interest & Example questions/prompts \\
\hline Pregnancy & $\begin{array}{l}\text { Tell me about your experiences of the pregnancy before you miscarried? } \\
\text { What were your expectations? }\end{array}$ \\
\hline Diagnosis & $\begin{array}{l}\text { Can you please tell me what happened when you miscarried? } \\
\text { Who was with you at the time? } \\
\text { Can you remember how you felt and what you thought at that time? }\end{array}$ \\
\hline Management & How were you cared for, by the hospital or GP, when you were miscarrying? \\
\hline Support & $\begin{array}{l}\text { What supports were offered to you in the hospital following your miscarriage? } \\
\text { Did you seek support from family and friends? }\end{array}$ \\
\hline Miscarriage: knowledge and experience & $\begin{array}{l}\text { Did you have any knowledge of miscarriage before your experience? } \\
\text { Did you seek information about miscarriage? } \\
\text { From your medical team? Family and/or friends? Websites? Support groups? }\end{array}$ \\
\hline Future pregnancies & $\begin{array}{l}\text { Have you been pregnant or considered another pregnancy since the miscarriage? } \\
\text { If they had a pregnancy: can you tell me how you felt during that pregnancy? }\end{array}$ \\
\hline
\end{tabular}

refined as similar themes were clustered together and subordinate and superordinate themes were identified. Patterns and connections across each individual transcript were examined. Finally, a master table of themes was created after each transcript was integrated into the final analysis. All analyses were carried out using Nvivo V.10 software (QSR International, Doncaster, Australia) by the primary author, a health sociologist. The analyses were then presented to the co-authors for review.

\section{FINDINGS}

Analysis of the data indicated six superordinate themes in relation to the participant's experience of miscarriage: acknowledgement of miscarriage as a valid loss, misperceptions of miscarriage, the hospital environment, management of miscarriage, support and coping, reproductive history and implications for future pregnancies.

\section{Acknowledgement of miscarriage as a valid loss}

As outlined in box 1, participants gave accounts of the devastation they experienced when they were told that they had miscarried. Participants stated that the miscarriages were all experienced differently but it was important to them that their miscarriages, irrespective of gestation, were acknowledged by healthcare professionals in the first instance but also more broadly throughout society. The men in this study felt that they could not experience the loss in the same manner as their partner. Men, however, did reiterate that although they did not experience the miscarriage physically, they were affected emotionally and, like the women, did go through a grieving process.

The acknowledgement of the loss through miscarriage, both by people and through ritual, was of importance. Participants discussed marking or remembering their loss in a variety of ways such as keeping a diary, writing of poems and songs or through the organisation of a funeral or similar ceremony. Some participants spoke of

\section{Box 1 Acknowledgement of miscarriage as a valid loss}

- "But the miscarriage itself, l'd say it was until then...and the whole discussion became a very public thing...it was only at that stage that I started to move on from it and that would have been five years, five years later and it was always something that would of upset me...it is hard to know what you are grieving for in a way because it is fleeting, you know the whole experience of being pregnant and then not being pregnant and thinking if I didn't remember this baby then who would." (P15, male, two miscarriages)

- "At this stage I think we had attended a couple of the, of the October, the ahhh annual ahhhh [prompt from interviewer; the annual service of remembrance] yeah. And again they are huge out pouring of grief, and of joy for life, but of grief. The people there and the support, but the fact that there are children and parents and grandparents, it just gives a sense that look it doesn't matter what age you are, doesn't matter how wealthy you are, doesn't matter what colour you are, we have all experienced this in our own way and we are all here today to remember that. And, I think for me, that, that was [pause] I haven't missed one yet and I'll still be going for another while yet. You know, that's a lovely outreach and very important." (P13 male, two miscarriages)

- "What I think happens, from my own experience, is I don't think it is recognised enough. Like cancer is recognised, god help us we have all had it and all those things. But a loss, it's a different loss when it's a child. They're still a child, they may not be grown but they're still a child" (P1, female, two miscarriages)

the importance of rituals particularly around the anniversary of the miscarriage in order to continue to acknowledge their loss. A number of participants remarked about the significance of attending the annual service of remembrance, which is organised by the hospital.

\section{Misperceptions of miscarriage}

All participants spoke about how there is not enough discussion relating to miscarriage in the public domain. 
It was not until the participants had experienced a miscarriage themselves that they were made aware of a history of miscarriage in their own family or with those in their close network of friends. As the participants recalled the experience of their first miscarriage, they recounted how naive they felt; they said that they had no inclination of what it was that they could and ultimately would experience. All participants asserted that increased discussion and awareness of miscarriage should be promoted in a wide range of contexts beginning with health education in school (box 2).

\section{The hospital environment and management of miscarriage}

When the participants spoke about how they were treated in the hospital, they remarked about how divergent an experience it was. The participants stated that any negative experiences in the hospital were related to the administration and/or physical design of the hospital specifically relating to the emergency department and the general clinics. When the women were miscarrying, they first attended the emergency department and found it difficult to be sitting in the waiting area surrounded by women attending with varying symptoms. This was considered one of the hardest aspects of the miscarriage experience as they felt they could not express any emotion (eg, anger or upset) relating to their loss, as they did not wish to distress the other pregnant women.

Once admitted for care in the emergency department, they felt that the physical space heightened their distress. With only a curtain between them, the participants recalled hearing other fetal monitors recording an audible heartbeat or conversations among staff, as they received confirmation that they had miscarried. It was felt that having to be in this environment while

\section{Box 2 Misperceptions of miscarriage}

- "I got spotting and I thought surely it's not going to happen again, cause they [people] always say one spontaneous [miscarriage] but you never (pause) but I think with miscarriage people just don't talk about it and they just don't think that it happens to everybody and they don't think it is as common as it is until you talk to other people about it. So I think the perception I would have had was if you had one you're not really likely to have another, that's what I thought." (P3, female, four miscarriages)

- "A friend of mine in work is pregnant and it's her first pregnancy and she's not kind of as worried as I am for her. She is oblivious and naïve and while l'm thinking 'oh god' she is saying 'it's fine'." (P7, female, two miscarriages)

- "Well when I did have the miscarriage and I said it to people, everyone says 'oh you know I had one' and it all comes out from the woodwork and em everyone knows someone who has had a miscarriage. It's so common how could you not but people generally don't talk about it...you don't have the knowledge...people need to know that this can happen." (P11, female, three miscarriages) miscarrying exacerbated the distress experienced by participants, who as a result believed that the hospital administration should be more sensitive to the situation. The women recalled how the early pregnancy clinic provided them with a better environment as there was more privacy which allowed them to more openly express their worry, anxiety or upset (box 3 ).

Participants experienced anxiety about attending the hospital to get tests over a number of days to confirm the loss of their baby. This was relatively impractical for some with work commitments, but was also difficult as they did not want to reattend the hospital to face the inevitable diagnosis. Many of the women expressed how they had suspected that something was wrong but had no knowledge of what to expect or what is considered normal while miscarrying. Those who miscarried at a later gestation discussed how they were wholly

Box 3 The hospital environment and management of miscarriage

"We came straight up here [the maternity hospital] and we went into the emergency place downstairs and we were seen straight away. But there were other patients and staff behind curtains, we were behind ours waiting on the doctor to come round. And there were nurses in there chatting and they were laughing and chatting and jokes and stuff, which they are entitled to have...but I was there with [husband] and we were worried sick that we were losing our baby and the doctor came in and she went through all the things and said 'No, I can't find a fetal heartbeat, it's gone'. Well, I started roaring crying, I was so upset but all the life was happening all around us, carrying on you know happily in behind the curtains...it was absolutely horrendous. But they organised for me to come back to the early pregnancy clinic, you know I didn't have to speak to anybody we just left the hospital [pause] that was hard." (P8, female, seven miscarriages)

- "That was hugely traumatic, cause em, I didn't miscarry the same as the last time it just went on and on and on. I was in and out of here [maternity hospital] every second day for blood tests. The first day they went up a bit and then they went down a bit and then it was kind of, like, and it was just two weeks really of turmoil." (P4, female, three miscarriages)

- "I woke up an hour later and I just completely haemorrhaged and I passed out a couple of times. Then I got in the bath and em, I was saying god people should warn people or prepare people if they are going to have miscarriages, cause I didn't know what was happening to me. And em what I excreted was unbelievable cause I was 12 weeks. And I started vomiting and I passed out again and then he rang the hospital. I tried talking to the hospital but I couldn't get the words out I was so weak at this point, you know, and they told me to come straight in. So I did and they killed me [slang: were annoyed with me] when I got in cause they said I should've called the ambulance." (P3, female, three miscarriages)

- "The first and the last were spontaneous and the last two I had to take medication but it would of happened inevitably but I, I just wanted to speed up [the miscarriage]..." (P5, female, four miscarriages) 
unprepared for the extent of the bleeding when they miscarried (box 3). When women had a choice, most chose to have some form of medical intervention. A number of factors influenced the decision to choose to intervene with women citing other commitments such as having to take care of other children in the family.

\section{Support and coping}

Keeping busy helped participants cope with their loss; this was particularly evident in the participants who already had children. Participants were hesitant to receive formal support by way of counselling and most opted for support from family, friends and/or support groups instead. Men felt that their primary role was to support their partners through the loss and, at times reluctantly, while planning subsequent pregnancies. During subsequent pregnancies, the participants disclosed that high levels of anxiety were experienced. They spoke of how they navigated through the pregnancy focusing on specific gestational weeks as goals, including exceeding the gestation they had experienced their miscarriage(s) at, as well as those coinciding with clinic appointments at the maternity hospital. Many of the participants detailed how these actions meant they could not fully enjoy the experience of being pregnant.

Throughout the subsequent pregnancy(ies), participants indicated their satisfaction with the service offered to them in the early pregnancy clinic. It was felt that the staff in the clinic were knowledgeable and cared for the women in a sensitive and understanding manner. The early pregnancy clinic provided reassurance to participants by facilitating appointments whereby the women could be scanned at earlier gestations and more frequently. Of those who were under the care of the specialist bereavement team, both men and women commented on the emotional support provided to them by the specialist midwife. The relationship between the women and midwife, in particular, was considered vital as they felt that these midwives, and the dedicated team, truly cared about their welfare and well-being (box 4).

\section{Reproductive history and implications for future pregnancies}

Whether there were children in the family before the miscarriage made a difference to how the experience impacted on each individual. Those who already had children were better able to reassure themselves that they could successfully get pregnant and give birth. Participants who did not have children before experiencing a miscarriage recalled their concerns about their health, behaviour and/or fertility (box 5).

Medical investigations, such as karyotyping, are not offered to women unless they have experienced recurrent miscarriage (three consecutive miscarriages). ${ }^{24}$ Participants expressed frustration that these tests were not offered to them following a second miscarriage. This dissatisfaction was heightened in women who felt

\section{Box 4 Support and coping}

"I was upset for a good while after but I had the other three [children] to keep me going [slang: busy] with school and everything...I had the D\&C the same week as my daughter's communion, so I had to just go ahead and get on with things you know, I had to be happy for her." (P10, female, two miscarriages)

- "I'd say we were slightly different in that if we had called it a day at the end of number seven, we both would have been extremely disappointed but you know I think, em, it's more about protection I suppose, I didn't want to have to go through it again. The decision was extremely difficult, now mean [wife] was very much in favour of going forward and trying again, em, I would have been a bit more reticent I suppose, em a bit more, you know, a bit more nervous about it. Obviously she had major concerns but you I think, I think it was a case of a tough decision but we just went for it." (P9, male, seven miscarriages)

- "I love babies and if someone was to say on Friday that you are pregnant and you are going to have to have the baby tomorrow, I would say yeah that's great but I just can't do the, the nine months of worrying." (P7, female, two miscarriages)

- "I went up to the [early pregnancy clinic] and they said "the next time you get pregnant call us here and come in and we will do a scan, we will do an early scan, we will give you that reassurance'. That made a huge difference, it made a huge difference because it felt like ok someone is not saying 'yeah, yeah, yeah move it along, move it along, next person' someone is actually saying 'we care about you, we know this is hard and the next time you get pregnant we know it's going to be distressful for the first few weeks so come in and we will give you scans'. And they were so good about it and when I did get pregnant it was one of the first calls I did make." (P12, female, two miscarriages)

Box 5 Reproductive history and implications for future pregnancies

- "We already had a loss, I know they were two, two different losses but I was thinking not again, what is going on, is there something wrong with me, am I ever going to have children." (P1, female, two miscarriages)

- "One of the things that I asked for was an appointment with [the specialist in pregnancy loss]to have tests done to see why I was having the miscarriages but I was told I would have to have 3 miscarriages before they would see me and I was kind of thinking, do they not take age into account? You know, you have to have three and I think two is an adequate level at my age. If I was in my twenties maybe you'd manage the three but not at my age." (P4, female, three miscarriages)

that other risk factors, such as advancing maternal age, should be considered (box 5).

\section{DISCUSSION}

The findings of this qualitative study indicate that the experience of miscarriage has a considerable impact on men and women. Findings from this study support what 
has been reported by others, that there is a need for increased awareness in relation to the frequent occurrence of miscarriage. Miscarriage is a common occurrence, yet as revealed by these participants it is not until a miscarriage was experienced that the participants were made aware of these high rates. A study from the USA also indicated that people believe that miscarriage is a rare complication of pregnancy. ${ }^{25}$ The participants from this study believed that improvement of information provision would be beneficial in allowing individuals to better prepare for the possibility that their pregnancy could end in miscarriage and, if it does occur, that support is available.

Second, given that a cause cannot be determined in as many as $50 \%$ of miscarriages, it was felt that having this information in advance may alleviate some of the guilt experienced. Participants emphasised that such information provision should also focus on the physical aspects of miscarrying. These findings mirror those of Moohan et $a l,{ }^{26}$ whereby women felt unprepared when miscarrying spontaneously and were questioning of whether what they had experienced was normal. Wong et $a l^{27}$ support this finding by detailing how miscarriage may be a physically traumatic event as women may experience considerable and sudden pain, loss of blood and may need to be hospitalised. Similar to the longitudinal study by Côté-Arsenault, ${ }^{28}$ the participants in this study indicated how pregnancy following miscarriage was stressful. There is a need for improved communication between healthcare professionals and patients to better counsel patients through the miscarriage and provide reassurance in subsequent pregnancies.

One coping strategy adopted by men and women was focusing on commitments, particularly taking care of other children in the family. In a review of the literature on grief following miscarriage, Brier states that having living children has also been used as an indicator for the importance attached to the pregnancy. This belief is based on the assumption that the absence of living children is associated with a relatively greater desire for children. ${ }^{29}$ Wong et $a l^{27}$ also highlight how, given this belief, it is also assumed that women with children will be less emotionally distressed and are less likely to receive emotional support from nursing staff. In contrast, the findings from this study illustrated that these participants were affected emotionally and did go through a grieving process irrespective of gestation of the pregnancy loss or whether they had living children or not. The findings also indicated the importance that healthcare professionals acknowledge miscarriage and how appreciative participants were of the support given to them.

It has been documented that men and women grieve differently following miscarriage in the literature, ${ }^{30} 31$ and these findings are also reflected in the accounts of the participants in this study. Similar to Johnson and Puddifoot, ${ }^{31}$ the men in this study indicated that they were less likely to openly discuss the miscarriage unless prompted by another person with a similar experience. This was also the case with discussing the impact of the miscarriage on them with their partners with the men identifying their primary role as that of a support to their partner. However, as outlined by Brier, ${ }^{29}$ this could suggest differences in the general expression of emotion and grief rather than affective reactions to miscarriage. Although the men in this study did not actively seek out support, they did reiterate that certain experiences and rituals were helpful for their grieving process as they allowed them to mark and remember their loss.

Participants in this study were reasonably satisfied with the care provided to them by the hospital. However, a number of shortcomings with the system were identified. When miscarrying, the first contact with the maternity hospital was with the emergency room. It was felt that waiting for extended periods of time in an area with other pregnant women was particularly difficult and a situation which hospital management should be more sensitive to. Wong et $a l^{27}$ outlined that in previous studies women believed that medical staff do not consider miscarriage as either important or an emergency and considered medical staff insensitive and unsympathetic about accommodation. Our findings build on these results whereby participants identified this insensitivity to be as a result of the hospital setting rather than medical staff. Participants were appreciative of staff, especially those whom they considered to be knowledgeable and those who displayed understanding and compassion. The dedicated early pregnancy clinic was an environment they believed could be further developed to enhance the care currently provided to women when they are miscarrying.

Consistent with a number of other studies, ${ }^{14} 27$ all the participants expressed a desire to determine the cause of the miscarriage. Participants expressed dissatisfaction that they were ineligible to have tests to fully investigate the cause of their miscarriage as they had not experienced the requisite three consecutive miscarriages. In our study, this perceived inadequacy in service provision was amplified in women of advancing maternal age. As Brier $^{29}$ outlines, maternal age can potentially influence an individual's goals with regard to childbearing. Advancing maternal age in combination with a number of losses experienced by a woman may impact on the duration and intensity of grief experienced. The women in this study expressed dissatisfaction with their ineligibility for investigations, maintaining that staff should appreciate that although they had not experienced recurrent miscarriage, there were other risk factors, such as their age, to be considered.

As part of the analysis, it is important to consider any factors which may influence the results. The participants in the study all made reference to the dedicated early pregnancy loss clinic. This clinic is staffed by a dedicated pregnancy loss team. Such a dedicated clinic is not available in all hospitals. Thus, the presence of such a team in the hospital may have raised awareness about miscarriage among other medical staff and influenced how they cared for the participants sampled here. It is important to note, that although a qualitative methodology was 
deemed appropriate for this study, the findings of such studies are context-specific. The experiences of the women and men in this study may or may not reflect the experiences of those who attend other units with differing resources and practices. Notwithstanding these limitations, given the level of agreement with other studies, we feel that these results add additional insight into the experiences of miscarriage.

\section{CONCLUSIONS}

This study highlights that a thorough investigation of the underlying causes of miscarriage and continuity of care in subsequent pregnancies are priorities for those who experience miscarriage. The provision of appropriate clinical information as well as supportive information when counselling individuals who are experiencing a miscarriage is important. Consideration should be given to the manner in which women who have not experienced recurrent miscarriage but have other potential risk factors for miscarriage could be followed up in clinical practice.

Twitter Follow Sarah Meaney @sarahmeaney5

Acknowledgements The authors are grateful to the participants for participating in the study and giving of their time freely.

Contributors SM and KOD contributed to and were responsible for the conception and design of the study. SM and NS were responsible for data collection. SM was responsible for transcription, data analysis and the initial drafting of the article. SM, PC, NS and KOD contributed to revising the manuscript critically for important intellectual content; final approval of the version to be published and the decision to submit the article for publication.

Funding This research received no specific grant from any funding agency in the public, commercial or not-for-profit sectors.

Competing interests None declared.

Ethics approval Ethical approval for the study was provided by the Clinical Research Ethics Committee of the Cork Teaching Hospitals (CREC; Reference: ECM 4 (iii) 10/01/12).

Provenance and peer review Not commissioned; externally peer reviewed.

Data sharing statement No additional data are available.

Open Access This is an Open Access article distributed in accordance with the Creative Commons Attribution Non Commercial (CC BY-NC 4.0) license, which permits others to distribute, remix, adapt, build upon this work noncommercially, and license their derivative works on different terms, provided the original work is properly cited and the use is non-commercial. See: http:// creativecommons.org/licenses/by-nc/4.0/

\section{REFERENCES}

1. Simmons RK, Singh G, Maconochie N, et al. Experience of miscarriage in the UK: qualitative findings from the National Women's Health Study. Soc Sci Med 2006;63:1934-46.

2. Maconochie N, Doyle P, Prior S, et al. Risk factors for first trimester miscarriage-results from a UK-population-based case-control study. BJOG 2007;114:170-86.

3. Adolfsson A. Applying Heidegger's interpretive phenomenology to women's miscarriage. Psychol Res Behav Manag 2010;3:75-9.

4. Murphy $\mathrm{F}$. The experience of early miscarriage from a male perspective. J Clin Nurs 1998;7:325-32.
5. Nanda K, Peloggia A, Grimes D, et al. Expectant care versus surgical treatment for miscarriage. Cochrane Database Syst Rev 2006;(2):CD003518.

6. Saraiya M, Berg CJ, Shulman $\mathrm{H}$, et al. Estimates of the annual number of clinically recognized pregnancies in the United States, 1981-1991. Am J Epidemiol 1999;149:1025-9.

7. Lee C, Slade P. Miscarriage is a traumatic event: a review of the literature and new implications for intervention. J Psychosom Res 1996;40:235-44.

8. Lok IH, Neugebauer R. Psychological morbidity following miscarriage. Best Pract Res Clin Obstet Gynaecol 2007;21: 229-47.

9. Nikcevic AV, Tunkel SA, Kuczmierczyk AR, et al. Investigation of the cause of miscarriage and its influence on women's psychological distress. Br J Obstet Gynaecol 1999;106:808-13.

10. Geller PA, Kerns D, Klier CM. Anxiety following miscarriage and the subsequent pregnancy: a review of the literature and future directions. J Psychosom Res 2004;56:35-45.

11. Craig M, Tata $P$, Regan L. Psychiatric morbidity among patients with recurrent miscarriage. J Psychosom Obstet Gynaecol 2002;23:157-64.

12. Kagami M, Maruyama T, Koizumi T, et al. Psychological adjustment and psychosocial stress among Japanese couples with a history of recurrent pregnancy loss. Hum Reprod 2012;27:787-94.

13. Klock SC, Chang G, Hiley A, et al. Psychological distress among women with recurrent spontaneous abortion. Psychosomatics 1997;38:503-7.

14. Serrano F, Lima ML. Recurrent miscarriage: psychological and relational consequences for couples. Psychol Psychother 2006;79:585-94.

15. Swanson KM, Connor S, Jolley SN, et al. Contexts and evolution of women's responses to miscarriage during the first year after loss. Res Nurs Health 2007;30:2-16.

16. Gerber-Epstein P, Leichtentritt RD, Benyamini Y. The experience of miscarriage in first pregnancy: the women's voices. Death Stud 2008;33:1-29.

17. Limbo R, Glasser JK, Sundaram ME. "Being sure": women's experience with inevitable miscarriage. MCN 2014;39:165-74.

18. Wojnar DM, Swanson KM, Adolfsson AS. Confronting the inevitable: a conceptual model of miscarriage for use in clinical practice and research. Death Stud 2011;35:536-58.

19. Swanson KM, Karmali ZA, Powell SH, et al. Miscarriage effects on couples' interpersonal and sexual relationships during the first year after loss: women's perceptions. Psychosom Med 2003;65:902-10.

20. Biggerstaff $D$, Thompson AR. Interpretive phenomenological analysis (IPA): a qualitative methodology of choice in health care research. Qual Res Psychol 2008;5:214-24.

21. Smith JA, Flowers $\mathrm{P}$, Larkin M. Interpretive phenomenological analysis: theory method and research. London: SAGE Publications, 2009.

22. Willig C. Introducing qualitative research in psychology. 2nd edn. New York: Open University Press, 2008.

23. Meaney S, Lutomski JE, Corcoran P, et al. PPO.50 Evaluation of non-response in the Women's Health Cohort Study. Arch Dis Child Fetal Neonatal Ed 2014;99:A166-168.

24. RCOG Green-top Guideline No. 17. The investigation and treatment of couples with recurrent first-trimester and second-trimester miscarriage. Royal College of Obstetricians and Gynaecologists, April 2011.

25. Bardos J, Hercz D, Friedenthal J, et al. A national survey on public perceptions of miscarriage. Am J Obstet Gynaecol 2015;125:1313-20.

26. Moohan J, Ashe RG, Cecil R. The management of miscarriage results from a survey at one hospital. J Reprod Health Infant Psycho 1994;12:17-19.

27. Wong MKY, Crawford TJ, Gask L, et al. A qualitative investigation into women's experiences after a miscarriage: implications for the primary healthcare team. Br J Gen Pract 2003;53:697-702.

28. Côté-Arsenault $D$. Threat appraisal, coping, and emotions across pregnancy subsequent to perinatal loss. Nurs Res 2007;56:108-16.

29. Brier N. Grief following miscarriage: a comprehensive review of the literature. J Womens Health 2008;17:451-64.

30. Beutel M, Willner H, Deckardt R, et al. Similarities and differences in couples' grief reactions following a miscarriage: results from a longitudinal study. J Psychosom Res 1996;40:245-53.

31. Johnson MP, Puddifoot JE. The grief response in the partners of women who miscarry. Br J Med Psychol 1996;69(Pt 4):313-27. 